to trace the connection which subsists between storms and Barometric differences.

We have also in these journals papers on Ozone, from Dr. Mitchell and Prof. Crum Brown; and in the physioogical branch of the science we have observations on crops, trees, birds, \&c., besides an interesting paper by Dr. Mitchell, on the cause of some of the pernicious effects of polar winds.

Besides the Fournals of the Scottish Meteorological Society, we have received two pamphlets written by $\mathrm{Mr}$. Charles Chambers, Director of the Bombay Observatory, which are of much value to men of science as thoroughly scientific discussions of phenomena observed with instruments of precision. In one of these, entitled "The Normal Winds of Bombay," we have a full analysis of the climate of that part of India as far as the element of wind is concerned.

In another pamphlet by the same author, forming pari of the Transactions of the Royal Society of London, we have the magnetic phenomena of Bombay discussed in a very able manner after the method first introduced by General Sir E. Sabine and followed now by most magneticians. If we have yet made little advance in assigniiig the causes of magnetic variations, we have at least in such pages as these a solid foundation upon which to build, and our progress in terrestrial magnetism in this respect contrasts favourably with what we have achieved in former years.

BALFOUR STEWART

\section{DONKIN'S ACOUSTICS}

Acoustics: Theoretical. Part 1. By W. F. Donkin, M.A., F.R.S., \&c., Savilian Professor of Astronomy, Oxford. Pp. 202. (Clarendon Press, 1870.)

IF the Delegates of the Clarendon Press are able to carry out their programme, it will be possible before long for English students to learn Physics in their native language. Besides Thomson and Tait's "Natural Philosophy," which, if completed in the same way as it has been begun, will be a book for a nation to be proud of, they promise us a series of separate educational treatises on the several branches of Physics. Of these there are already published Dr. Balfour Stewart's excellent treatise on Heat, and the work mentioned at the head of this notice. This, unhappily, is only a fragment, forming part of the generai theoretical introduction to a treatise on Sound and the principles of Music which the author did not live to write. But, although its quality is such as to make us keenly sensible of the loss which English science has suffered by the author's removal before he had completed the work, the part that is published treats of subjects of so fundamental a nature, and so little dependent on what would have followed them, that its intrinsic value is probably not much lessened by the absence of the remainder.

The first chapter begins with a general description of the mechanism of the ear ; this is followed by an explanation of the mode of representing vibratory movements by periodic curves, and a discussion of the nature of pitch, and of the principle of the superposition of vibrations, as bearing upon the distinction between noises and musical sounds, and upon the general mode of perception of sounds by the ear. The second chapter is headed "Miscellaneous Definitions and Propositions," and is chiefly occupied with the mode of defining musical intervals, and with the statement of their most important relations. The third chapter treats of the analytical representation of simple harmonic vibrations, and of the composition of vibrations at right angles to each other. The fourth chapter treats of the properties of the harmonic curve, of the composition of harmonic curves, and of Fourier's Theorem. The fifth, sixth, and seventh chapters are devoted to the vibrations of elastic strings, the greater part of the sixth being occupied with the description and experimental treatment of the important subject of forced oscillations, and an appendix to the same chapter with the mathematical theory of them. The eighth chapter treats of the longitudinal vibrations; and the ninth and last, of the transverse vibrations of elastic rods. The greater part of the book is addressed to mathematical readers, but much of it may be read with profit by students whose mathematical acquirements are very moderate. The evidence throughout the work of the author's mastery of his subject gives to it a freshness and individuality which are in strong contrast to the characteristics of the undigested compilations which form so large a part of the literature of physics.

C. FOSTER

\section{OUR BOOK-SHELF}

Daily Readings in Natural Science. By Rev. J. Robertson. (London: C. Bean. 1870.)

THIs book has been prepared for beginners in the study of Natural Science ; it is clearly and pleasantly written each day in the week during a term has its subject allotted to it, either on Natural History, Physics, Botany, Astronomy, Natural Phenomena, Chemistry, Geology, Manufactures, Animal Physiology, or Applied Chemistry. The chapters are short, with questions at the end of each for the use of teachers. Mr. Robertson has written several other similar books, which he uses in his own school, and his success as a teacher lends great weight to the following extract from the preface:- "It is hardly necessary to descant lengthily upon the advantage of introducing science teaching into schools. The author, however, may be pardoned for giving his experience of adding science to the usual course of studies among his own boys. The science classes in his school had not long been established before he found that those boys who took no interest in their ordinary work soon manifested a quickness and brightness in dealing with natural objects that was quite remarkable, so much so, that after the first three months he doubled the time devoted to science by the upper form, and commenced new classes for the benefit of the middle and lower forms. Speaking generally, the study of Natural Science quickens a boy's powers of observation and comparison; he learns to express his thoughts in proper logical order, his judgment is developed, and the tendency that all boys have to form hasty conclusions is checked and tempered." To these we may join the following practical hints on conveying scientific instruction to schoolboys, in a notice to teachers at the end of the book:- "To be of real use science must be taught practically. Experiment and deduction should go hand in hand, and a boy ought never to be called upon to commit a fact to memory the truth of which he has not previously seen demonstrated. This of course presupposes perfection in the way of apparatus and specimens, a state of things that may possibly exist some day at such magnificent centres of learning as Eton, Harrow, or Rugby, but the boy who by circumstances is obliged to pass his days at smaller establishments, must take for granted a large number of the facts with which he stores his memory. But the ingenious teacher will see a thousand ways of demonstrating facts to his pupils with the outlay of very little money or time. The short course of 